\title{
Design of the Violence and Stress Assessment (ViStA) study: A randomized controlled trial of care management for PTSD among predominantly Latino patients in safety net health centers
}

\author{
Lisa S. Meredith ${ }^{\mathrm{a}, \mathrm{b}, *}$, David P. Eisenman ${ }^{\mathrm{a}, \mathrm{c}}$, Bonnie L. Green ${ }^{\mathrm{d}}$, Stacey Kaltman ${ }^{\mathrm{d}}$, Eunice C. Wong ${ }^{\mathrm{a}}$, \\ Bing Han ${ }^{a}$, Andrea Cassells ${ }^{\text {, }}$, Jonathan N. Tobin ${ }^{\text {e,f,g }}$ \\ ${ }^{a}$ RAND Corporation, 1776 Main Street, Santa Monica, CA 90407-2138, USA \\ ${ }^{\mathrm{b}}$ VA HSRED Center for the Study of Healthcare Provider Behavior, 16111 Plummer Street (152), North Hills, CA 91343, USA \\ c Division of General Internal Medicine and Health Services Research, Department of Medicine, David Geffen School of Medicine at UCLA, 10833 Le Conte Ave, Los Angeles, \\ CA 90095, USA \\ d Department of Psychiatry, Georgetown University Medical School, 4000 Reservoir Road NW Suite 120, Washington, DC 20007, USA \\ e Clinical Directors Network (CDN), 5 W 37th St \# 10, New York, NY 10018, USA \\ ${ }^{\mathrm{f}}$ Department of Epidemiology and Population Health, Albert Einstein College of Medicine of Yeshiva University, 1300 Morris Park Ave, Bronx, NY 10461, USA \\ ${ }^{g}$ Center for Clinical and Translational Sciences, The Rockefeller University, 1230 York Avenue, New York, NY 10065, USA
}

\section{A R T I C L E I N F O}

\section{Article history:}

Received 28 January 2014

Received in revised form 6 April 2014

Accepted 9 April 2014

Available online 18 April 2014

\section{Keywords:}

Post-traumatic stress disorder

Care management

Safety net Federally Qualified Health Centers (FQHCs)

Hispanic/Latino

Primary care

Integrating primary care and mental health

\begin{abstract}
A B S T R A C T
Posttraumatic stress disorder (PTSD) is a common problem in primary care. Although effective treatments are available, little is known about whether such treatments are effective within the context of Federally Qualified Health Centers (FQHCs) that serve as national "safety nets" for providing primary care for low income and underinsured patients. The Violence and Stress Assessment (ViStA) study is the first randomized controlled trial (RCT) to test the impact of a care management intervention for treating PTSD in FQHCs. To develop a PTSD management intervention appropriate for lower resource FQHCs and the predominantly Latino patients they serve, formative work was conducted through a collaborative effort between researchers and an FQHC practice-based research network. This article describes how FQHC stakeholders were convened to review, assess, and prioritize evidence-based strategies for addressing patient, clinician, and system-level barriers to care. This multi-component care management intervention incorporates diagnosis with feedback, patient education and activation; navigation and linkage to community resources; clinician education and medication guidance; and structured crossdisciplinary communication and continuity of care, all facilitated by care managers with FQHC experience. We also describe the evaluation design of this five-year RCT and the characteristics of the 404 English or Spanish speaking patients enrolled in the study and randomized to either the intervention or to usual care. Patients are assessed at baseline, six months, and 12 months to examine intervention effectiveness on PTSD, other mental health symptoms, health-related quality-of-life, health care service use; and perceived barriers to care and satisfaction with care.
\end{abstract}

(c) 2014 Elsevier Inc. All rights reserved.

\footnotetext{
* Corresponding author at: RAND Corporation, 1776 Main Street, M3W, Santa Monica, CA 90407-2138, USA. Tel.: + 1310393 0411x7365; fax: + 1 3102608152.

E-mail address: lisa_meredith@rand.org (L.S. Meredith).
}

\section{Introduction}

Post-traumatic stress disorder (PTSD) is a common mental disorder associated with substantial psychological, physical and social consequences. PTSD affects over $10 \%$ of people in the 
United States [1,2] and its prevalence is high among patients seen in primary care settings, such as Federally Qualified Health Centers (FQHCs), with rates ranging from 9\% to 23\% [3-9]. PTSD often co-occurs with depression, substance abuse, other psychological problems [10-13], and medical conditions [14-20], and is associated with poor physical health functioning [21] and poor quality of life [14,18,21-23]. PTSD also heightens risk for marital instability [24], teenage childbearing [25], lower educational attainment [26,27], and unemployment [28]. Finally, PTSD and related impairment are associated with an annual loss of over $\$ 3$ billion in work productivity $[29,30]$.

Better coordination between primary care and mental health services is an important priority for FQHCs, which serve as the national "safety net" for the poor and under- or uninsured. However, there are no models readily available for addressing PTSD in these settings. As with other mental health problems, individuals with PTSD visit primary care clinicians (PCCs) more often than mental health specialty clinicians for their initial treatment [31]. Because the identification and management of PTSD are not routine in primary care settings such as FQHCs, this mental illness may be underdiagnosed [32]. This is in part because physicians are reluctant to inquire about personal traumas [33-36]. Other general obstacles at the patient-, clinician-, and systems-levels impede care, such as patients' low mental health literacy and perceived stigma about seeking mental health care; clinicians' time constraints for dealing with psychological issues; gaps in clinician treatment knowledge about mental health and its treatment; and difficulty accessing mental health specialists.

Only a few studies have examined the effectiveness of primary care collaborative intervention for the improvement of anxiety disorders, including PTSD [37-42], and results are promising. Though these studies have yielded promising results, none have focused specifically on a substantial contribution to furthering knowledge of FQHCs and underserved patients. Therefore, it is unknown whether such approaches are feasible and effective in FQHCs that provide care for predominantly underserved populations, which often include a high proportion of Latino, uninsured, or publicly insured patients $[43,44]$.

Some evidence suggests that collaborative care interventions for PTSD may be adapted and implemented to address the needs of this population [45]. However, it is necessary to contextualize that care to the type of trauma and cultural factors. For example, the literature shows that the types of traumatic events that immigrant Latina women experience are primarily domestic violence, community violence, and witnessing violence and these trauma experiences tend to be of amplified brutality if they occurred in their country of origin suggesting a greater adverse impact on mental health $[11,46,84]$. Querying Latinas about the intensity of the exposure and to fully understand their experiences is likely to facilitate assessment and treatment.

More intensive screening and intervention may also be needed for this population since both Latina women and Latino men, whom tend to experience political and community violence, do not readily disclose their traumatic experiences $[47,48]$. In addition, many Latinas, especially immigrants who lack strong social networks and therefore report being socially isolated even if their family is with them $[48,49]$. Moreover, there is some evidence that battered women can be prevented from using needed services by male partners who may use physical or emotional methods to control their partner's behavior [50]. Therefore, patient engagement strategies and readily accessible adjunctive non-medical community services (i.e., social, legal) are needed [49,51]. For example, interpersonal violence experiences are associated with a greater need for legal and social service support compared with those not reporting interpersonal violence.

Finally, health literacy obstacles combined with language discordance with health care providers for monolingual Spanish speakers and culture differences are common in this population [52]. Thus, it is crucial to create intervention materials that are at the appropriate language level and that are translated and culturally adapted and to employ bilingual and bicultural intervention staff who understand these needs.

This article describes the design and evaluation of a PTSD care management intervention for limited-resource settings serving low-income populations with complex health and social problems. Violence and Stress Assessment (ViStA) is the first large randomized controlled trial (RCT) to evaluate the effectiveness of a multi-faceted care manager (CM) based intervention for PTSD in FQHCs.

\section{Method}

\subsection{Intervention development}

The ViStA intervention was developed as part of an exploratory/developmental study that relied on an academiccommunity partnership between RAND and the Clinical Directors Network (CDN - www.CDNetwork.org), an established Practice-Based Research Network (PBRN) that works with FQHCs that provide comprehensive community-based primary care and preventive care to the underserved [53]. The intervention was tailored for FQHC settings and underserved populations based upon input from clinical staff at FQHC study sites; further details can be found elsewhere [48,54].

Briefly, through this formative work, we utilized group process methods [55] based on modified Delphi techniques $[47,56,57]$ to identify key barriers to providing evidence-based PTSD care and strategies for addressing those barriers. We identified a panel of nine clinical staff from six FQHCs (5 physicians, 1 nurse, 1 social worker, and 2 non-clinical site administrators) to participate in the intervention design process. The panel was asked to: 1 ) review and prioritize the barriers that are most important to address for managing patients with PTSD in FQHCs, 2) discuss alternative evidence-based strategies for improving PTSD care, and 3) select the most promising approach for improving PTSD care that is feasible and appropriate for the setting and patients served.

To achieve these objectives, we asked the panel to provide ratings in two rounds of brief surveys and to participate in an in-person, half-day meeting that convened in November 2006. Specifically, we distributed a "pre-work" packet that included a 1-page survey to be returned in advance of the meeting. The survey asked participants to rank a set of common barriers and to identify a strategy for addressing each of the barriers. The top-rated barriers are shown in the first column of Table 1. Based on evidence (middle column of Table 1 ), we provided 
Table 1

Barriers Identified, Proposed Evidence-Based Strategies for Addressing Barriers, and Intervention Components Adapted for the ViStA Study.

\begin{tabular}{|c|c|c|}
\hline Barriers & Evidence-Based Strategies & ViStA Intervention Components \\
\hline $\begin{array}{l}\text { Patient-Level: } \\
\text { 1. Perceived stigma } \\
\text { 2. Low mental health literacy }\end{array}$ & $\begin{array}{l}\text { 1. Educating and activating/motivating } \\
\text { patients about mental health problems } \\
\text { [58-61] } \\
\text { 2. Linking patients to non-medical services } \\
\text { in the community }[36,62-65]\end{array}$ & $\begin{array}{l}\text { 1. CMs reviewed NIMH PTSD brochures (in English or Spanish) with } \\
\text { patients during the initial visit prior to seeing the PCC and used } \\
\text { motivational interviewing techniques to encourage self-care and } \\
\text { problem-solving } \\
\text { 2. CMs used locally-tailored resource guides to refer patients to } \\
\text { non-medical community services }\end{array}$ \\
\hline $\begin{array}{l}\text { Clinician-Level: } \\
\text { 3. Limited treatment knowledge } \\
\text { and time } \\
\text { 4. Difficulty finding MHSs }\end{array}$ & $\begin{array}{l}\text { 3. Providing PCCs feedback about patient } \\
\text { diagnosis }[66,67] \\
\text { 4. Educating clinicians on practice guidelines } \\
\text { and evidence-based treatments [68] }\end{array}$ & $\begin{array}{l}\text { 3. Research team provided feedback about patients meeting PTSD } \\
\text { diagnostic criteria placed in study chart } \\
\text { 4. Research team provided on-site initial training and interim Webinar } \\
\text { booster training to PCCs and MHSs about evidence-based treatments for } \\
\text { PTSD and equipped PCCs with laminated medication guides }\end{array}$ \\
\hline $\begin{array}{l}\text { System-Level: } \\
\text { 5. Poor care coordination with } \\
\text { mental health } \\
\text { 6. Unavailability of MHSs at the } \\
\text { center or in the community }\end{array}$ & $\begin{array}{l}\text { 5. Coordinating primary and specialty care } \\
\text { for persons with mental illness [69] } \\
\text { 6. Enhancing continuity of patient care and } \\
\text { planned follow-up care [70] }\end{array}$ & $\begin{array}{l}\text { 5. CMs provided structured communication about patients to PCCs and } \\
\text { MHSs } \\
\text { 6. CMs provided continuous care to patients over one year in up to } 15 \\
\text { encounters }\end{array}$ \\
\hline
\end{tabular}

Notes: CM: care manager; PCC: primary care clinician; MHS: mental health specialist.

potential strategies for ranking that might be effective in addressing these barriers. Participants were also given the opportunity to suggest additional strategies. Prior to the panel meeting, the research team tallied the pre-work survey results and prepared brief presentations to review the study aims and explain the meeting goals. The results provided a launching point for the working session, where the top three ranked barrier-strategy combinations were presented to the group. The remaining time was structured around three key questions for each combination: 1) What are the specific details of the strategy for addressing the barrier? 2) How receptive are you to an intervention for PTSD in the FQHC setting? And 3) How feasible and sustainable is the intervention? After the meeting, the research team summarized the discussions and shared them with the group.

The panel then recommended a potential intervention approach with promise for addressing the top barriers and improving the identification and management of PTSD. This approach included six components. The first is patient education (using National Institute of Mental Health PTSD brochures [58] placed in the waiting rooms and handed to each person screened) and training auxiliary staff to screen patients for PTSD before a PCC visit. Educating the clinicians and providing guidelines about evidence-based treatments for PTSD, particularly on appropriate prescribing practices, were additional strategies suggested to address clinician-level barriers. Other strategies included improving the feedback mechanism between primary care and mental health, and devising systems for improving continuity of patient treatment (e.g., medication refills). An Advisory Group consisting of the same stakeholders was formed subsequently, meeting via biweekly conference calls, to provide input to the ViStA team as we developed the intervention and the grant application (for the randomized trial) to insure its feasibility, compatibility for implementation, and cultural appropriateness with the patient population. Examples of cultural adaptations [52] include translating all study materials into Spanish at a low literacy level to ensure comprehension, employing bilingual Latinas in study recruitment and intervention delivery roles, and training CMs to rephrase technical terms to be more culturally meaningful. Specifically, because Latinos may be difficult to engage in mental health treatment, they are using a 3-point engagement scale and strategies from motivational interviewing to encourage engagement. CMs also received training about how to present clinical information in the context of Latino cultural and religious contexts and how to use expressions common among the predominantly Dominican and Puerto Rican Latinos in our sample (e.g., "ataques de nervios" to describe uncontrollable shouting, crying attacks, shouting, and aggression). We also made adjustments to our study to enhance feasibility for clinical staff (e.g., training busy staff in hour-long modules at each $\mathrm{FQHC}$ to minimize disruption) and to tailoring $\mathrm{CM}$ communications to PCC preferences within the existing administrative system structures in FQHCs.

\subsection{ViStA intervention}

The resulting ViStA intervention design, based on the formative, partnered work, is a multi-faceted program that includes components and strategies implemented through a CM to overcome patient-, clinician-, and system-level barriers (column 1 of Table 1) that were operationalized based on the FQHC stakeholder input and evidence-based strategies (column 2 of Table 1). The ViStA PCM intervention has six key components (column 3 of Table 1). The first component, patient education and activation is facilitated through $\mathrm{CMs}^{\prime}$ use of a National Institute of Mental Health PTSD brochure and motivational interviewing techniques [58-61]. We used these materials, in part, because they are available in both English and Spanish. The second component, dissemination of non-medical community resources, includes the provision of locally-tailored information based on previously established $\mathrm{FQHC}$ referral linkages and facilitating new linkages [62-65]. We researched and identified resources for both English-speaking and Spanishspeaking patients and our resource directory included service agencies that focused on Latinos' needs (i.e., immigration, English as a second language). This was a particularly important aspect of the intervention because of the need to make other community services accessible to a population that has broad service needs beyond those available from a medical setting. The third component involves patient screening and evaluation for PTSD diagnosis with structured feedback provided to PCCs 
$[66,67]$. The fourth component, clinician education on practice guidelines, includes onsite and online continuing medical education (CME)-accredited sessions (available in the Webcast Library at www.CDNetwork.org) and a laminated medication guide [68]. The fifth component, structured cross-disciplinary communication, included regular meetings between CMs, PCCs, and specialty mental health providers, as well as CMs' participation in weekly supervision with the study psychiatrist [69]. This was important because we expected that PCCs would feel more confident about treating PTSD if they had relatively effortless access to mental health services and established relationships with adjunct services [48]. The sixth component, continuity of patient care, is facilitated by the CMs through an initial in-person visit in conjunction with a scheduled medical visit with the PCC and up to 14 additional follow-up contacts (by phone or in-person) over a year [69,70]. All of the intervention components are implemented through the CMs, except for the clinician education component, which was delivered by a physician-researcher (DE) and other members of the study team.

CMs manage their intervention patient panel using a secure, encrypted ACCESS database or patient registry. The registry includes multiple modules for documenting and tracking information obtained by the $\mathrm{CM}$ during the initial in-person intervention visit and follow-up contacts including PTSD symptoms, medications, PCC treatment plans, patient self-management goals, resource referrals and utilization, and appointment dates.

The one-year intervention has eight key steps (Fig. 1). The first step involves patient screening by the recruitment coordinator (RC) using a brief 6-item screener [71] to identify those at risk for PTSD. For those with a positive brief screen, the RC assesses patients for exposure to traumatic events using the Stressful Life Events Screening Questionnaire (SLES-Q) $[10,72]$ and administers the Clinician Administered PTSD Scale (CAPS) $[73,74]$ to assess for a diagnosis of PTSD (Step 2). Patients who meet the criteria for PTSD are randomized to either the $\mathrm{CM}$ intervention or usual care and then complete the baseline evaluation assessment. Once the baseline assessment is completed, the CM imports screening data, trauma information, patient PTSD diagnosis, and contact information into the patient registry (Step 3).

Thereafter, the CM calls patients to arrange an initial Back-to-Back visit generally within two weeks of the baseline assessment (Step 4). During the visit the CM first meets with the patient in person for 45 minutes to collect information about PTSD symptom severity via the 17 -item PTSD Checklist-civilian version (PCL-C) [75]; assessing suicide risk, stress, and resource needs; providing education about PTSD; engaging the patient to actively participate in their PTSD treatments; and using motivational interviewing techniques to encourage behavior change [59-61]. The CM also enters information about the patient into the registry and then transcribes relevant information for the patient to share with the PCC in the visit following the CM assessment (Step 5).

The PCC then meets with the patient and documents the management plan in the study visit worksheet (Step 6). Treatment may involve watching and waiting, starting the patient on a PTSD medication [68], referring the patient to a psychiatrist for medication evaluation and management,
Study Entry

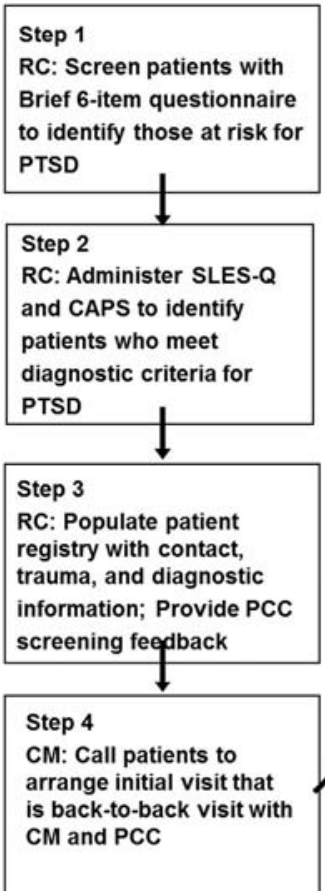

\section{Back-to-Back Visit}

Step 5

CM: Meet with patient for 45 minutes to provide education

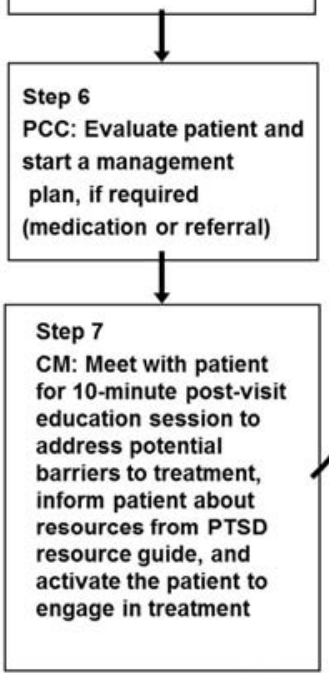

\section{Follow-Up Contacts}

Step 8

CM: Call patients for

follow-up at pre-specified

intervals

( 1 week after initial visit,

every 2 weeks for a month,

and each month thereafter

throughout 12-month

intervention) to:

Provide education about

treatment response and

adherence

Monitor patient's PTSD

symptoms and other clinical

information in patient

registry

Provide feedback to PCC

and MHS on treatment

progress as needed

\author{
RC $=$ Recruitment Coordinator \\ $\mathbf{C M}=$ Care Manager \\ PCC $=$ Primary Care Clinician \\ MHS $=$ Mental Health Specialist
}

Fig. 1. Overview of ViStA intervention. 
and/or referring the patient for psychotherapy with a mental health specialist.

Following the visit with the PCC, the CM conducts a brief, 10-minute meeting with the patient (Step 7) to review the treatment plan, answer any questions, assess and address barriers to treatment adherence, provide relevant information from the PTSD resource directory (guided by the CM), and complete a personal plan for the patient. At the end of this session, the CM arranges for the next contact with the patient and enters information from the PCC into the patient registry. We chose to use this approach because it facilitates communication with both the PCC by providing synthesized information about the patient's condition and because it can help engage the patient in care by preparing the patient for the encounter with the PCC and in optimizing the productivity of that encounter [39]. In addition, the post-PCC visit session with the $\mathrm{CM}$ enhances care by reviewing the treatment plan with the patient to increase adherence and preparing them for the follow-up care.

After the visit (Step 8), the CM contacts the patient by phone for follow-up within one week of the visit, every two weeks for a month, and then subsequently once a month throughout the 12-month intervention period for a total of up to 15 contacts with a patient. During these scheduled follow-up calls, the $\mathrm{CM}$ reassess the patient for PTSD symptoms (using the PCL), provides information about treatment progress, answers patient questions, shares information on resources and community linkages, and schedules the next call. Throughout the intervention period, the $\mathrm{CM}$ provides feedback to the PCC and mental health specialist (if applicable) on the patient's progress, barriers the patient faces in adhering to the treatment plans, and changes in the patient's PTSD status. Due to a diversity of structures among the FQHCs, CMs use a range of strategies to communicate with the PCCs about CM cases (e.g., at monthly clinician meetings, between patient visits, and through email and notes placed in patient charts). The CMs compile monthly reports from aggregate patient data collected through the patient registries to track the number of patients with PTSD who are assessed, treated, and referred for care.

\subsection{PTSD care managers}

Because of resource constraints inherent in FQHCs, we hired non-clinical CMs from the community. The two bachelors-level half-time CMs were bilingual (in Spanish) Latinas with experience in community health service and knowledge of cultural issues in this FQHC patient population. CMs were trained to provide care management for PTSD using the study protocol. Initial training consisted of 1.5 days of didactic instruction with role-plays followed by booster training mid-way throughout the intervention. Training covered all facets of the $\mathrm{CM}$ role, including contacting patients, using the patient registry, coordinating care with clinical staff (PCCs and mental health professionals), using psychiatric supervision, educating and activating patients (including basic principles of motivational interviewing), following-up and monitoring patients, assessing for PTSD symptoms using the PCL, and filing monthly reports. All patients at a given site see the same $\mathrm{CM}$ to avoid $\mathrm{CM}$ variation within site.

CMs meet weekly for one hour to review cases with the study psychiatrist. CMs share challenging patient cases and receive advice for how to best help those patients, as well as guidance and suggestions for modifying treatment plans. In addition, the weekly $\mathrm{CM}$ calls with the psychiatrist are used to share self-care strategies with the goal of preventing burnout among the CMs.

\subsection{Evaluation design}

The ViStA study is a patient-level randomized controlled trial currently evaluating the efficacy of a PTSD Care Management (PCM) intervention compared with usual care using differences in differences analysis of outcomes before and at six and 12 months after the intervention. In addition, ViStA is assessing the effects of the intervention implementation and examining the direct costs of the PCM program compared with usual care. Both Clinical Directors Network (CDN) and RAND Institutional Review Boards approved ViStA procedures before patient recruitment began.

\subsection{Study measures}

Our primary outcomes include mental health and functioning, health and mental health service use, patient satisfaction with care, and perceived barriers to care (Table 4). We will assess these outcomes at baseline, six, and 12 months. We also collected several secondary measures, which include process measures for assessing intervention fidelity (e.g., adjunctive support services, medications, CBT components). Secondary measures will be also be used as covariates in main analyses (e.g., functional impairment, intervention exposure, perceived need for treatment). Other secondary measures (e.g., resilience,

Table 2

Summary of Federally Qualified Community Health Center (FQHC) characteristics.

\begin{tabular}{|c|c|c|c|c|c|c|c|c|c|c|}
\hline $\mathrm{FQHC}$ & $\begin{array}{l}\text { Onsite } \\
\mathrm{BH}\end{array}$ & \# Psychiatrists* & $\begin{array}{l}\text { \# Social } \\
\text { Workers }\end{array}$ & $\begin{array}{l}\text { \# Adult } \\
\text { users }\end{array}$ & \# AM PCCs & $\begin{array}{l}\text { Weekly patient } \\
\text { volume }\end{array}$ & \% Latino/a & \% Women & \% Uninsured & $\%$ Medicaid \\
\hline A & Yes & 1 & 2 & 8,000 & $9^{\dagger}$ & 330 & 56 & 59 & 37 & 50 \\
\hline B & No & 0 & 1 & 20,000 & 4 & 400 & 65 & 60 & 20 & 50 \\
\hline C & No & 1 & 1 & 9,000 & 5 & 450 & $60 s$ & 65 & 10 & 65 \\
\hline D & Yes & 5 & 13 & 9,000 & 7 & 600 & 65 & 70 & 20 & 70 \\
\hline E & No & 0 & 1 & 4,000 & 2 & 120 & 80 & 65 & 40 & 50 \\
\hline $\mathrm{F}$ & Yes & 1 & 2 & 3,500 & 9 & 700 & 80 & 65 & 50 & 10 \\
\hline G & Yes & 1 & 5 & 11,300 & 6 & 400 & 65 & 65 & 11 & 69 \\
\hline
\end{tabular}

Notes. $\mathrm{BH}=$ behavioral health; AM = adult medicine; PCC = primary care clinician (adult medicine); Indicates psychiatrist(s) except for site F which had a psychiatric nurse practitioner; psychiatrists were part-time at sites $C$ and $F .^{\dagger} 4$ of 9 are residents. 
Table 3

Characteristics of ViStA participants $(\mathrm{N}=355)$.

\begin{tabular}{|c|c|c|}
\hline & $\mathrm{N}$ & Percent \\
\hline Age (mean and standard deviation) & 42.4 & 12.2 \\
\hline Women & 286 & 80.6 \\
\hline \multicolumn{3}{|l|}{ Race/ethnicity } \\
\hline Hispanic/Latino & 183 & 51.8 \\
\hline Black & 125 & 35.4 \\
\hline White & 21 & 6.0 \\
\hline Other & 24 & 6.8 \\
\hline \multicolumn{3}{|l|}{ Marital status ${ }^{\mathrm{a}}$} \\
\hline Single & 201 & 57.6 \\
\hline Separated/divorced/widowed & 76 & 21.8 \\
\hline Married & 45 & 12.9 \\
\hline Member of unmarried couple & 27 & 7.7 \\
\hline Has one child or more & 279 & 79.7 \\
\hline \multicolumn{3}{|l|}{ Education } \\
\hline$<$ High school & 137 & 38.9 \\
\hline 12 years & 116 & 33.0 \\
\hline$>12$ years & 99 & 28.1 \\
\hline U.S. born ${ }^{\mathrm{b}}$ & 276 & 81.4 \\
\hline \multicolumn{3}{|l|}{ Health insurance } \\
\hline No insurance & 26 & 7.4 \\
\hline Medicaid & 286 & 81.2 \\
\hline Medicare & 7 & 2.0 \\
\hline Other government insurance & 20 & 5.7 \\
\hline Private insurance & 13 & 3.7 \\
\hline \multicolumn{3}{|l|}{ No. of chronic medical conditions } \\
\hline 0 & 113 & 32.7 \\
\hline 1 & 73 & 21.1 \\
\hline 2 & 62 & 17.9 \\
\hline$\geq 3$ & 98 & 28.3 \\
\hline \multicolumn{3}{|l|}{ No. of lifetime traumas } \\
\hline 1 & 10 & 2.9 \\
\hline 2 & 29 & 8.3 \\
\hline$\geq 3$ & 311 & 88.9 \\
\hline Probable major depression (PHQ-9 > 9) & 181 & 48.4 \\
\hline Severe anxiety symptoms (GAD > 15) & 160 & 45.2 \\
\hline Severe somatic symptoms (PHQ15 > 15) & 116 & 33.2 \\
\hline Hazardous alcohol use (AUDIT $>8$ men $/>3$ women) & 65 & 18.4 \\
\hline Probable drug abuse/dependence (DAST-10 > 3) & 31 & 8.8 \\
\hline
\end{tabular}

Notes. Values are numbers and percentages except for age which is mean and standard deviation.

a 6 patients did not disclose this information.

b 16 patients did not disclose this information.

coping, and social support) will be employed as mediators and moderators in supplemental analyses.

\section{Results}

\subsection{FQHC characteristics}

The intervention is being implemented in seven different FQHCs in the New York/New Jersey Metropolitan area. These FQHCs span three of the five boroughs of NYC, Westchester, NY, and Northern NJ. Table 2 summarizes selected characteristics of these FQHCs. When the intervention was first implemented, four sites had onsite mental health care. However, two of the mental health components were independent mental health divisions accredited by the NY State Department of Health. These divisions served patients outside of primary care and were thus difficult to access. Additionally, one of the mental health divisions was closed during the study. Thus, mental health resources are more limited than anticipated. The study FQHCs vary in size and in ratio of clinicians to patients. The largest site, which has
20,000 adult users, initially had only four PCCs (which is a ratio of 5,000 patients per clinician), although three additional clinicians were hired after the study began. In contrast, the smallest FQHC, which has only 3,500 users, has nine PCCs (a ratio of 389 patients per clinician). Patient volume also varies from a low of 110 patients per week to as many as 700 patients per week. Between $59 \%$ and $75 \%$ of the patients seen in these centers are Latino and between 56\% and $80 \%$ were women. Most of the patients have Medicaid insurance or are uninsured.

\subsection{Sample size}

Our study was designed with a targeted sample size of 400 (effective sample size $=320$ after attrition). This will allow us to detect an effect size of .32 S.D. on primary outcomes using two-sample comparisons, and an effect size .19 S.D. using three-wave longitudinal data, both under the standard setting (significance level $=.05$, power $=.8$ ). These effect sizes are considered small in the standard power analysis in behavioral sciences. In addition, these effect sizes are plausible since they are smaller than the findings in the literature reported effect sizes .40 and .21 in cross-sectional and longitudinal analysis respectively.

\subsection{Study sample and patient characteristics}

Approximately 8,300 patients were approached for participation in the study and 4,815 met the initial inclusion criteria (have a scheduled or walk-in appointment with a PCC, no physical or cognitive disabilities, 18-65 years of age, and plans to continue receiving care at that $\mathrm{FQHC}$ for the next year) and completed the brief screener for PTSD symptoms. Of those, 30\% were at-risk for PTSD (defined as a cut-off of 14). Most patients at-risk consented to the study (72\%) and had a DSM-IV PTSD diagnosis (69\%) according to the CAPS. The overall rate of PTSD was $8 \%$ in the total eligible sample. A total of 404 patients were enrolled into the trial. Patients within the participating FQHCs were randomized to each of the two study conditions. The baseline sample includes 206 patients randomized to the ViStA intervention and 198 randomized to usual care; 184 (89\%) and 171 (86\%) patients completed the baseline interview, respectively. The six and 12-month follow-up data collection are in progress.

The majority of ViStA participants who have completed baseline interviews $(\mathrm{N}=355)$ are women (Table 3$)$. Half of the sample is Hispanic/Latino (51.8\%) and over a third is Black (35.4\%). A high proportion of the ViStA participants have not finished high school and is either uninsured (7.4\%) or on subsidized insurance (81.2\%). Nearly all of the ViStA participants reported having experienced three or more traumatic events. A large proportion of these patients also have one or more chronic medical conditions. Comorbid mental health and substance use symptoms are common, with nearly half meeting criteria for probable major depression (48.4\%) and severe anxiety (45.2\%). A third of the patients have probable somatization disorder (33.2\%) according to the PHQ and $27.2 \%$ of the participants meet criteria for either hazardous alcohol use $(18.4 \%)$ or drug abuse/dependence (8.8\%). 
Table 4

ViStA baseline measures.

\begin{tabular}{|c|c|}
\hline Measure & Source(s) \\
\hline \multicolumn{2}{|l|}{ Mental health and functioning } \\
\hline Brief 6-item PTSD screener & Lang \& Stein, 2005 [71] \\
\hline Trauma exposure & SLES-Q, Goodman et al., 1998; Green et al., 2006 [10,72] \\
\hline PTSD diagnosis and symptoms & Clinician Administered PTSD scale (CAPS), Blake et al., 1995; Weathers et al., $2001[73,74]$ \\
\hline Health-related quality of life & SF12/MHI5, Ware Jr. et al., 1995; Ware Jr. \& Sherbourne, 1992 [77,78] \\
\hline Functional impairment & Sheehan Disability Scale, Leon et al., 1997 [79] \\
\hline \multicolumn{2}{|l|}{ Health and mental health service use } \\
\hline Physical/mental health service use & Partners in Care (PIC), Wells et al., 2000 [80] \\
\hline CBT components & PIC, Jaycox et al., 2003 [81] \\
\hline Awareness of intervention Exposure & PIC, Rubenstein, et al., 1999 [82] \\
\hline Medications & PIC, Unützer et al., 2001 [83] \\
\hline Adjunctive support services & Community Partners in Care (CPIC), unpublished \\
\hline Problem recognition & National Comorbidity Study-Revised (NCS-R), Koenen et al., 2003; Alegria et al., 2004 [84,85] \\
\hline Perceived need for treatment & NCS-R, Koenen et al., 2003; Mojtabai et al., 2002 [85,86] \\
\hline Patient satisfaction with care & Hays et al., 1999 [87] \\
\hline Perceived barriers to care & PIC, unpublished \\
\hline \multicolumn{2}{|l|}{ Comorbidity } \\
\hline Medical conditions & Charlson Comorbidity Index, Charlson et al., 1987; Charlson et al., 1984 [88,89] \\
\hline Somatization & Patient Health Questionnaire (PHQ), Spitzer et al., 1999 [90] \\
\hline Depression symptom severity & PRIME-MD PHQ-9; Spitzer et al., 1999 [90] \\
\hline Anxiety symptom severity & GAD-7, Spitzer et al., 2006 [91] \\
\hline Alcohol and drug use & AUDIT, Babor et al., 2001 [92] \\
\hline Substance disorder & Drug Abuse Screening Test (DAST-10), Skinner, 1982; Yudko et al., 2007 [93,94] \\
\hline Stressful life experiences & Perceived Stress Scale, Cohen et al., 1983 [95] \\
\hline Resilience & CD-RISC, short form, Connor \& Davidson, 2003; Campbell-Sills \& Stein, 2007 [96,97] \\
\hline General coping & PIC; Sherbourne et al., 2004 [98] \\
\hline Religious coping & Tepper et al., 2001 [99] \\
\hline Social support & PIC; Sherbourne et al., 2004 [98] \\
\hline Relationship satisfaction & General Social Survey \\
\hline Chronic pain & PEG, Krebs et al., 2009 [100] \\
\hline Demographics & Standard items \\
\hline
\end{tabular}

\section{Discussion}

Only a few studies have explored the application and translation of primary care collaborative care models to improve anxiety disorders, including PTSD. Roy-Byrne et al. [40] examined the effectiveness of collaborative care for panic disorder in primary care and found significant improvement in patient quality of care, as well as clinical and functional outcomes, relative to usual care. The Coordinated Anxiety Learning and Management (CALM) study [42] found that the intervention was significantly associated with reduced anxiety and depression symptoms; decreased disability; improved quality of care [37,39]; and more anxiety-free days; with modest increases in healthcare expenditures over 18 months compared with usual care [38]. Furthermore, it was feasible to implement and acceptable by clinic staff [76]. There was no significant effect on PTSD symptoms, although this could have been due to the small number of patients with PTSD in the study. A recent study of collaborative care for PTSD in veterans (RESPECT-PTSD) did not find significant differences in symptoms or functioning, but did find that the intervention increased quality of care relative to usual care [41].

These studies have made a substantial contribution to furthering knowledge about the management of anxiety disorders in "real world" primary care settings. However, these settings, which are relatively well-resourced, academicallyaffiliated clinics, with patient populations who mostly have insurance and are predominantly White or veterans, are quite different from FQHCs and their underinsured and low resource patients including those whom are undocumented and have no legal access to some services. It is not known whether such approaches are feasible for community-based FQHCs that serve as the main system of care for these populations, which include a high proportion of minorities, including Latinos, other non-English speaking populations, and high levels of uninsured or publicly insured patients $[43,44]$. Collaborative care interventions may be adapted and implemented to address the needs of those with PTSD in cost-effective ways [62] and may include psycho-education, hybrid treatments, psycho-pharmacology, and systemslevel interventions that integrate mental health treatment into primary care settings [45].

ViStA was designed using an academic-community research-PBRN collaboration that considered formative data and evidence-based practices to improve PTSD care. The data collection and analysis are currently underway to assess the impact of this intervention $[39,40]$. ViStA will be the first randomized controlled study of a care management intervention for PTSD in low-resource FQHCs that provide primary care to many low-income, non-English speaking minority patients. The ViStA approach is grounded in previous work, and innovative in its application to this $\mathrm{FQHC}$ population. We chose to implement and adapt the components of the intervention that were previously tested and shown to be effective in higher resource environments to FQHC settings and patients.

The delivery of effective collaborative care intervention within $\mathrm{FQHC}$ settings can be challenging given that the patient population includes many low-income, uninsured patients from diverse backgrounds and with high rates of 
chronic trauma and multiple clinical co-morbidities. Some of the unique barriers identified in our formative work, include limited access to and affordability for specialty mental health care, make it even more challenging to engage and retain patients in treatment. Many of the patients seen in this study's FQHCs are immigrants and may return to their home countries for extended periods of time, contributing to discontinuity of care and medication non-adherence. Additionally, several FQHCs were shut down permanently or temporarily during the study period for reasons ranging from legal situations culminating in the incarceration of the FQHC Chief Executive Officer, to a catastrophic natural disaster (i.e., Super storm Sandy).

Despite the many challenges inherent in implementing a care management intervention in these types of settings and patient populations, ViStA was successful in engaging seven different FQHCs. ViStA has recruited over 400 patients with clinical diagnoses of PTSD. The ViStA study will test the effects of the intervention on the management of PTSD, further adding to the science of care improvement. In addition, ViStA will examine the implementation fidelity as well as its cost and cost-effectiveness.

\section{Conclusion}

This study will fill a gap in our knowledge of how to intervene with PTSD patients in low-resourced communitybased primary care settings where most patients prefer to be treated [48]. Additionally, we will learn whether the intervention can be implemented in FQHCs, and whether it is clinically effective in settings where many patients may not have realistic referral options for specialty care and where the PCC may also serve as the primary mental health clinician. The longer-term goal of ViStA is to disseminate more broadly an effective model tailored to these populations and settings to improve the quality of care, quality of life, and clinical outcomes for those who are exposed to trauma and suffer from PTSD.

\section{Acknowledgements}

This research was supported by a grant to Dr. Meredith from the National Institute of Mental Health/NIMH (R01MH082768, R01MH082768-02S1, R01MH082768-04S1). The authors appreciate the following Community Health Centers for partnering on the study: Morris Heights Health Center, Bronx, NY, Joseph P. Addabbo Health Center - Main Site, Far Rockaway, NY, Joseph P. Addabbo Health Center - Central Avenue, Far Rockaway, NY Ryan NENA Health Center, NY, NY, Soundview Health Center, Bronx, NY, Open Door Family Health Center, Port Chester, NY, Metropolitan Family Health Network, Jersey City, NJ. We acknowledge the clinicians and staff who participated in the advisory group, including Sara Ventre, RN, Gloria Leacock, MD, and Crystal Foy, BA, of Community Healthcare Network, NY, NY; Alfonso Chan, MD, Joseph P. Addabbo Health Center, Queens, NY; Lauren Machin, CSW, and Diane Traver, MD, of Morris Heights Health Center, Bronx, NY, Crystal Jordan, JD, Soundview Health Center; Arthur Berger, MD, Urban Health Plan, Bronx, NY; Harsha Tripathi, Plainfield Neighborhood Health Center, Plainfield, NJ. We also thank CDN staff, including: Marleny Diaz-Gloster, MPH Tzyy Jye Lin, MPH, Rosario Hinojosa, Jennifer Rodriguez, Tatiana Carillo, Mala
Nimalasuriya, Carrie Goodman, MPH, Carmen Rodriguez, Ajeenah Haynes, PhD, Parisa Faysar, Elizabeth Leonard, Omesh Persaud, and Taralah Washington for their assistance in identifying, recruiting, interviewing, translating, patient care management and translating materials from patient research participants. We thank Susan Paddock for her statistical guidance, Dolly Dahdal for help with project assistance; and Catherine Chao and Michael Woodward for manuscript preparation. Earlier versions of this work were presented at the International Society for Traumatic Stress Society meetings (Montreal, Quebec, Canada, November 2010; Mexico City, Mexico, May 2012; Los Angeles, CA, November 2012, and Philadelphia, PA, November 2013).

\section{References}

[1] Kessler RC, Chiu WT, Demler O, Merikangas KR, Walters EE. Prevalence, severity, and comorbidity of 12-month DSM-IV disorders in the National Comorbidity Survey Replication. Arch Gen Psychiatry 2005;62:617-27

[2] Kessler RC, Sonnega A, Bromet E, Hughes M, Nelson CB. Posttraumatic stress disorder in the National Comorbidity Survey. Arch Gen Psychiatry 1995;52:1048-60.

[3] Gillock KL, Zayfert C, Hegel MT, Ferguson RJ. Posttraumatic stress disorder in primary care: prevalence and relationships with physical symptoms and medical utilization. Gen Hosp Psychiatry 2005;27:392-9.

[4] Kroenke K, Spitzer RL, Williams JB, Monahan PO, Lowe B. Anxiety disorders in primary care: prevalence, impairment, comorbidity, and detection. Ann Intern Med 2007;146:317-25.

[5] Liebschutz J, Saitz R, Brower V, Keane TM, Lloyd-Travaglini C, Averbuch T, et al. PTSD in urban primary care: high prevalence and low physician recognition. J Gen Intern Med 2007;22:719-26.

[6] Magruder KM, Frueh BC, Knapp RG, Davis L, Hamner MB, Martin RH, et al. Prevalence of posttraumatic stress disorder in Veterans Affairs primary care clinics. Gen Hosp Psychiatry 2005;27:169-79.

[7] Neria Y, Gross R, Olfson M, Gameroff MJ, Wickramaratne P, Das A, et al. Posttraumatic stress disorder in primary care one year after the 9/11 attacks. Gen Hosp Psychiatry 2006;28:213-22.

[8] Stein MB, McQuaid JR, Pedrelli P, Lenox R, McCahill ME. Posttraumatic stress disorder in the primary care medical setting. Gen Hosp Psychiatry 2000;22:261-9.

[9] Taubman-Ben-Ari O, Rabinowitz J, Feldman D, Vaturi R. Posttraumatic stress disorder in primary-care settings: prevalence and physicians' detection. Psychol Med 2001;31:555-60.

[10] Green BL, Krupnick JL, Chung J, Siddique J, Krause ED, Revicki D, et al. Impact of PTSD comorbidity on one-year outcomes in a depression trial. J Clin Psychol 2006;62:815-35.

[11] Kaltman S, Green BL, Mete M, Shara N, Miranda J. Trauma, depression, and comorbid PTSD/depression in a community sample of Latina immigrants. Psychol Trauma 2010;2:31-9.

[12] Kessler RC, Wang PS. The descriptive epidemiology of commonly occurring mental disorders in the United States. Annu Rev Public Health 2008;29:115-29.

[13] Rodriguez BF, Weisberg RB, Pagano ME, Machan JT, Culpepper L, Keller MB. Frequency and patterns of psychiatric comorbidity in a sample of primary care patients with anxiety disorders. Compr Psychiatry 2004;45:129-37.

[14] Boscarino JA. Diseases among men 20 years after exposure to severe stress: implications for clinical research and medical care. Psychosom Med 1997;59:605-14

[15] Boscarino JA. Posttraumatic stress disorder and mortality among U.S. Army veterans 30 years after military service. Ann Epidemiol 2006; $16: 248-56$

[16] Green BL, Kimerling R. Trauma, PTSD, and health status. In: Schnurr PP, Green BL, editors. Trauma and health: Physical health consequences of exposure to extreme stress. Washington, DC: American Psychological Association; 2004. p. 13-42.

[17] O'Toole BI, Catts SV. Trauma, PTSD, and physical health: an epidemiological study of Australian Vietnam veterans. J Psychosom Res 2008;64:33-40.

[18] Schnurr PP, Spiro III A, Paris AH. Physician-diagnosed medical disorders in relation to PTSD symptoms in older male military veterans. Health Psychol 2000;19:91-7.

[19] Seng JS, Graham-Bermann SA, Clark MK, McCarthy AM, Ronis DL. Posttraumatic stress disorder and physical comorbidity among female 
children and adolescents: results from service-use data. Pediatrics 2005; 116:e767-76.

[20] Walker EA, Gelfand A, Katon WJ, Koss MP, Von Korff M, Bernstein D, et al. Adult health status of women with histories of childhood abuse and neglect. Am J Med 1999;107:332-9.

[21] Zayfert C, Dums AR, Ferguson RJ, Hegel MT. Health functioning impairments associated with posttraumatic stress disorder, anxiety disorders, and depression. J Nerv Ment Dis 2002;190:233-40.

[22] Malik ML, Connor KM, Sutherland SM, Smith RD, Davison RM, Davidson JR. Quality of life and posttraumatic stress disorder: a pilot study assessing changes in SF-36 scores before and after treatment in a placebo-controlled trial of fluoxetine. J Trauma Stress 1999;12:387-93.

[23] Ouimette P, Cronkite R, Henson BR, Prins A, Gima K, Moos RH. Posttraumatic stress disorder and health status among female and male medical patients. J Trauma Stress 2004;17:1-9.

[24] Kessler RC, Walters EE, Forthofer MS. The social consequences of psychiatric disorders, III: probability of marital stability. Am J Psychiatry 1998;155:1092-6.

[25] Kessler RC, Berglund PA, Foster CL, Saunders WB, Stang PE, Walters EE. Social consequences of psychiatric disorders, II: Teenage parenthood. Am J Psychiatry 1997;154:1405-11.

[26] Ceyhan E, Ceyhan AA. Earthquake survivors' quality of life and academic achievement six years after the earthquakes in Marmara, Turkey. Disasters 2007;31:516-29.

[27] Kessler RC, Foster CL, Saunders WB, Stang PE. Social consequences of psychiatric disorders, I: Educational attainment. Am J Psychiatry 1995;152:1026-32.

[28] Ettner SL, Frank RG, Kessler RC. The impact of psychiatric disorders on labor market outcomes. Ind Labor Relat Rev 1997;51:64-81.

[29] Kessler RC. Posttraumatic stress disorder: the burden to the individual and to society. J Clin Psychiatry 2000;61(Suppl. 5):4-12 [discussion $3-4]$.

[30] Walker EA, Katon W, Russo J, Ciechanowski P, Newman E, Wagner AW. Health care costs associated with posttraumatic stress disorder symptoms in women. Arch Gen Psychiatry 2003;60:369-74.

[31] Wang PS, Berglund P, Olfson M, Pincus HA, Wells KB, Kessler RC. Failure and delay in initial treatment contact after first onset of mental disorders in the National Comorbidity Survey Replication. Arch Gen Psychiatry 2005;62:603-13.

[32] Olfson M, Tobin JN, Cassells A, Weissman M. Improving the detection of drug abuse, alcohol abuse, and depression in community health centers. J Health Care Poor Underserved 2003;14:386-402.

[33] McCauley J, Yurk RA, Jenckes MW, Ford DE. Inside "Pandora's box": abused women's experiences with clinicians and health services. J Gen Intern Med 1998;13:549-55.

[34] Sugg NK, Inui T. Primary care physicians' response to domestic violence. Opening Pandora's box. JAMA 1992;267:3157-60.

[35] Parsons LH, Zaccaro D, Wells B, Stovall TG. Methods of and attitudes toward screening obstetrics and gynecology patients for domestic violence. Am J Obstet Gynecol 1995;173:381-6 [discussion 6-7].

[36] Green BL, Kaltman SI, Frank L, Glennie M, Subramanian A, FrittsWilson M, et al. Primary care providers' experiences with trauma patients: A qualitative study. Psychol Trauma 2011;3:37-41.

[37] Craske MG, Stein MB, Sullivan G, Sherbourne C, Bystritsky A, Rose RD, et al. Disorder-specific impact of coordinated anxiety learning and management treatment for anxiety disorders in primary care. Arch Gen Psychiatry 2011;68:378-88.

[38] Joesch JM, Sherbourne CD, Sullivan G, Stein MB, Craske MG, Roy-Byrne P. Incremental benefits and cost of coordinated anxiety learning and management for anxiety treatment in primary care. Psychol Med 2012;42:1937-48.

[39] Roy-Byrne P, Craske MG, Sullivan G, Rose RD, Edlund MJ, Lang AJ, et al. Delivery of evidence-based treatment for multiple anxiety disorders in primary care: a randomized controlled trial. JAMA 2010;303:1921-8

[40] Roy-Byrne PP, Katon W, Cowley DS, Russo J. A randomized effectiveness trial of collaborative care for patients with panic disorder in primary care. Arch Gen Psychiatry 2001;58:869-76.

[41] Schnurr PP, Friedman MJ, Oxman TE, Dietrich AJ, Smith MW, Shiner B, et al. RESPECT-PTSD: Re-engineering systems for the primary care treatment of PTSD, a randomized controlled trial. J Gen Intern Med 2012;28:32-40.

[42] Sullivan G, Craske MG, Sherbourne C, Edlund MJ, Rose RD, Golinelli D, et al. Design of the Coordinated Anxiety Learning and Management (CALM) study: Innovations in collaborative care for anxiety disorders. Gen Hosp Psychiatry 2007;29:379-87.

[43] Fedovskiy K, Higgins S, Paranjape A. Intimate partner violence: how does it impact major depressive disorder and post traumatic stress disorder among immigrant Latinas? J Immigr Minor Health 2008;10: 45-51.
[44] Samson AY, Bensen S, Beck A, Price D, Nimmer C. Posttraumatic stress disorder in primary care. J Fam Pract 1999;48:222-7.

[45] Kaltman S, Hurtado de Mendoza A, Gonzales FA, Serrano A. Preferences for trauma-related mental health services among Latina immigrants from Central America, South America, and Mexico. Psychol Trauma 2014;6:83-91.

[46] Kaltman S, Hurtado de Mendoza A, Gonzales FA, Serrano A, Guarnaccia PJ. Contextualizing the trauma experience of women immigrants from Central America, South America, and Mexico. J Trauma Stress 2011;24:635-42.

[47] Dalkey ND. Delphi. Santa Monica, CA: RAND Corporation; 1967.

[48] Eisenman DP, Meredith LS, Rhodes H, Green B, Kaltman S, Cassells A, et al. PTSD in Latino patients: illness beliefs, treatment preferences, and implications for care. J Gen Intern Med 2008:23:1386-92.

[49] Hurtado-de-Mendoza A, Gonzales FA, Serrano A, Kaltman S. Social isolation and perceived barriers to establishing social networks among Latina immigrants. Am J Community Psychol 2014;53:73-82.

[50] Logan TK, Evans L, Stevenson E, Jordan CE. Barriers to services for rural and urban survivors of rape. J Interpers Violence 2005;20:591-616.

[51] Eisenman DP, Richardson E, Sumner LA, Ahmed SR, Liu H, Valentine J, et al. Intimate partner violence and community service needs among pregnant and postpartum Latina women. Violence Vict 2009:24:111-21.

[52] Ramos Z, Alegría M. Cultural adaptation and health literacy refinement of a brief depression intervention for Latinos in a low-resource setting. Cultur Divers Ethnic Minor Psychol 2014;20:293-301.

[53] Sardell A. Clinical networks and clinician retention: the case of CDN. J Community Health 1996;21:437-51.

[54] Meredith L, Eisenman D, Green B, Basurto-Dávila R, Cassells A, Tobin J. System factors affect the recognition and management of post-traumatic stress disorder by primary care clinicians. Med Care 2009;47:686-94.

[55] Fink A, Kosecoff J, Chassin M, Brook RH. Consensus methods: characteristics and guidelines for use. Am J Public Health 1984;74:979-83.

[56] Dalkey ND. The Delphi method: An experimental study of group opinion. Santa Monica, CA: RAND Corporation; 1969.

[57] Helmer D. Social technology. New York, NY: Basic Books; 1966.

[58] National Institute of Mental Health. Post-traumatic stress disorder. [cited 2013 June 24]; Available from: http://www.nimh.nih.gov/ health/publications/post-traumatic-stress-disorder-ptsd/nimh_ptsd_ booklet.pdf; 2008 .

[59] Miller WR, Moyers TB, Arciniega L, Ernst D, Forcehimes A. Training, supervision and quality monitoring of the COMBINE Study behavioral interventions. J Stud Alcohol Suppl 2005:188-95 [discussion 68-9].

[60] Miller WR, Rollnick S. Motivational interviewing: Preparing people for change. 2nd ed. New York: Guilford Press; 2002.

[61] Rollnick S, Miller WR, Butler C. Motivational interviewing in health care: Helping patients change behavior. New York: The Guilford Press; 2007.

[62] Kaltman S, Pauk J, Alter CL. Meeting the mental health needs of lowincome immigrants in primary care: a community adaptation of an evidence-based model. Am J Orthopsychiatry 2011;81:543-51.

[63] Wagner EH, Glasgow RE, Davis C, Bonomi AE, Provost L, McCulloch D, et al. Quality improvement in chronic illness care: a collaborative approach. Jt Comm J Qual Improv 2001;27:63-80.

[64] Wells KB, Jones L, Chung B, Dixon EL, Tang L, Gilmore J, et al. Community-partnered cluster-randomized comparative effectiveness trial of community engagement and planning or resources for services to address depression disparities. J Gen Intern Med 2013:28:1268-78.

[65] Zatzick D, Jurkovich G, Rivara FP, Russo J, Wagner A, Wang J, et al. A randomized stepped care intervention trial targeting posttraumatic stress disorder for surgically hospitalized injury survivors. Ann Surg 2012;257:390-9.

[66] Linn LS, Yager J. Screening of depression in relationship to subsequent patient and physician behavior. Med Care 1982;20:1233-40.

[67] Gilbody SM, House AO, Sheldon TA. Routinely administered questionnaires for depression and anxiety: systematic review. BMJ 2001;322: 406-9.

[68] National Institute for Clinical Excellence/NICE. Clinical guidelines CG26, post-traumatic stress disorder (PTSD): The management of PTSD in adults and children in primary and secondary care. March 2005 [cited 2013 June 24; Available from: http://www.nice.org.uk/ cg26].

[69] Pincus HA, Pechura CM, Elinson L, Pettit AR. Depression in primary care: linking clinical and systems strategies. Gen Hosp Psychiatry 2001;23:311-8.

[70] Wagner EH, Austin BT, Von Korff M. Organizing care for patients with chronic illness. Milbank Q 1996:74:511-44.

[71] Lang AJ, Stein MB. An abbreviated PTSD checklist for use as a screening instrument in primary care. Behav Res Ther 2005:43:585-94.

[72] Goodman LA, Corcoran C, Turner K, Yuan N, Green BL. Assessing traumatic event exposure: general issues and preliminary findings for 
the Stressful Life Events Screening Questionnaire. J Trauma Stress 1998; 11:521-42.

[73] Blake DD, Weathers FW, Nagy LM, Kaloupek DG, Gusman FD, Charney DS, et al. The development of a clinician-administered PTSD scale. J Trauma Stress 1995;8:75-90.

[74] Weathers FW, Keane TM, Davidson JRT. Clinician-administered PTSD scale: A review of the first ten years of research. Depress Anxiety 2001;13:132-56.

[75] Weathers FW, Litz BT, Huska JA, Keane TM. The PTSD checklist-civilian version (PCL-C). Boston, MA: National Center for PTSD; 1994.

[76] Curran GM, Sullivan G, Mendel P. Craske MG, Sherbourne CD, Stein MB, et al. Implementation of the CALM intervention for anxiety disorders: a qualitative study. Implementation science: IS, 7; 2012 1-11.

[77] Ware Jr JE, Kosinski M, Keller S. SF-12: How to score the SF-12 physical and mental health summary scales. 2nd ed. Boston, MA: The Health Institute, New England Medical Center; 1995.

[78] Ware Jr JE, Sherbourne CD. The MOS 36-item short-form health survey (SF-36). I. Conceptual framework and item selection. Med Care 1992;30:473-83.

[79] Leon AC, Olfson M, Portera L, Farber L, Sheehan DV. Assessing psychiatric impairment in primary care with the Sheehan Disability Scale. Int J Psychiatry Med 1997;27:93-105.

[80] Wells KB, Sherbourne C, Schoenbaum M, Duan N, Meredith L, Unützer $\mathrm{J}$, et al. Impact of disseminating quality improvement programs for depression in managed primary care: a randomized controlled trial. JAMA 2000;283:212-20.

[81] Jaycox LH, Miranda J, Meredith LS, Duan N, Benjamin B, Wells K. Impact of a primary care quality improvement intervention on use of psychotherapy for depression. Ment Health Serv Res 2003;5:109-20.

[82] Rubenstein LV, Jackson-Triche M, Unutzer J, Miranda J, Minnium K, Pearson ML, et al. Evidence-based care for depression in managed primary care practices. Health Aff 1999;18:89-105.

[83] Unützer J, Rubenstein L, Katon WJ, Tang L, Duan N, Lagomasino IT, et al. Two-year effects of quality improvement programs on medication management for depression. Arch Gen Psychiatry 2001;58:935-42.

[84] Alegria M, Vila D, Woo M, Canino G, Takeuchi D, Vera M, et al. Cultural relevance and equivalence in the NLAAS instrument: integrating etic and emic in the development of cross-cultural measures for a psychiatric epidemiology and services study of Latinos. Int J Methods Psychiatr Res 2004;13:270-88.

[85] Koenen KC, Goodwin R, Struening E, Hellman F, Guardino M. Posttraumatic stress disorder and treatment seeking in a national screening sample. J Trauma Stress 2003;16:5-16.

[86] Mojtabai R, Olfson M, Mechanic D. Perceived need and help-seeking in adults with mood, anxiety, or substance use disorders. Arch Gen Psychiatry 2002;59:77-84.
[87] Hays RD, Shaul JA, Williams VS, Lubalin JS, Harris-Kojetin LD, Sweeny $\mathrm{SF}$, et al. Psychometric properties of the CAHPS 1.0 survey measures. Consumer Assessment of Health Plans Study. Med Care 1999;37: MS22-31.

[88] Charlson M, Szatrowski TP, Peterson J, Gold J. Validation of a combined comorbidity index. J Clin Epidemiol 1994:47:1245-51.

[89] Charlson ME, Pompei P, Ales KL, MacKenzie CR. A new method of classifying prognostic comorbidity in longitudinal studies: development and validation. J Chronic Dis 1987;40:373-83.

[90] Spitzer RL, Kroenke K, Williams JB. Validation and utility of a selfreport version of PRIME-MD: the PHQ primary care study. Primary Care Evaluation of Mental Disorders. Patient Health Questionnaire. JAMA 1999;282:1737-44.

[91] Spitzer RL, Kroenke K, Williams JBW, Lowe B. A brief measure for assessing generalized anxiety disorder - The GAD-7. Arch Intern Med 2006;166:1092-7.

[92] Babor T, Higgins-Biddle J, Saunders J, Monteiro M. AUDIT The alcohol use disorders identification test: guidelines for use in primary care. Geneva: World Health Organization; 2001.

[93] Skinner HA. The drug abuse screening test. Addict Behav 1982;7: 363-71.

[94] Yudko E, Lozhkina O, Fouts A. A comprehensive review of the psychometric properties of the Drug Abuse Screening Test. J Subst Abuse Treat 2007;32:189-98.

[95] Cohen S, Kamarck T, Mermelstein R. A global measure of perceived stress. J Health Soc Behav 1983;24:385-96.

[96] Campbell-Sills L, Stein M. Psychometric analysis and refinement of the Connor-Davidson resilience scale (CD-RISC): Validation of a 10-item measure of resilience. J Trauma Stress 2007;20:1019.

[97] Connor KM, Davidson JR. Development of a new resilience scale: the Connor-Davidson Resilience Scale (CD-RISC). Depress Anxiety 2003;18: $76-82$.

[98] Sherbourne C, Schoenbaum M, Wells KB, Croghan TW. Characteristics, treatment patterns, and outcomes of persistent depression despite treatment in primary care. Gen Hosp Psychiatry 2004;26:106-14.

[99] Tepper L, Rogers SA, Coleman EM, Malony HN. The prevalence of religious coping among persons with persistent mental illness. Psychiatr Serv 2001:52:660-5.

[100] Krebs EE, Lorenz KA, Bair MJ, Damush TM, Wu J, Sutherland JM, et al. Development and initial validation of the PEG, a three-item scale assessing pain intensity and interference. J Gen Intern Med 2009;24: 733-8. 